\title{
Research on the Modern Idea of Running a High-level Private College
}

\author{
Wang Guan, Zhang Yan \\ Qifang Education Research Institute, Xi’an International University
}

Keywords: high-level; private college and university; idea of running a college or university

\begin{abstract}
To establish a high-level private college or university, the first prerequisite is to update the old idea, and to have a deliberation on these problems such as "what a high-level private college or university should be?”, "what kind of mission it needs to carry out?”, "what kind of function to it should perform?", and "how to carry out the mission and play a positive role?". These problems need to be solved by the modern colleges and universities. As an important part of the higher education, private college and university should not only follow the "university tradition" which is formed in the development of the college university, but also actively explore and summarize the modern college and university idea that is out of the actual situation of the colleges and universities and the characteristics of the times; at the same time, private college and university also should insist on the public welfare of private education, master the modern service conception and provide high-quality services to the society, and take diversified developmental roads.
\end{abstract}

The change of the society promotes the change of colleges and universities, and the reform of a college and university is firstly manifested in the aspect of renewal and adoption the advanced idea. To establish some high-level private colleges and universities is an important strategic countermeasure for the further development and transformation of the private higher education in China, and how to establish some high-level colleges and universities is an actual issue that we have to solve. What a high-level private college or university should to be, what are its mission and function, and how it should carry out its mission and play an active role? It is these problems that the modern college and university idea should answer. The right college and university idea can leads the private colleges and universities to go forward exactly.

\section{The Characteristics of the College and University Idea in Present Times}

University idea is a kind of systematic, theoretical and regular ideology that is related to the essence, property and functions of a university. Popularly speaking, university idea aims at answering these basic theoretical and practical problems as below---."what is the function of a university?", "what is a university?", "how to run a university?" and "what kind of university we should establish?" As the important institute of cultivating talents, the main functions of a traditional university is to cultivate the clergies, government officers, layers and doctors. School is the place where the teachers pass on their knowledge to their students, in school, there is no scientific research. Universities usually operate autonomously, and the teachers and students running their own affairs, and the scholars can teach and express their views freely. At the some time, the scholars who are form all over the world gather in the universities, teachers and students could choose the city and the university they like, this show the internationalization of the universities.

As the relationship of the three parts----university and the society and government----becomes closer and closer, the society service function of university becomes prominent. University should not only pass on and spread truth, and explore new knowledge, but also be more open and socialized, and not be restrained by some traditional conceptions; at the some time, it should provide all-round services to the society. In the era of knowledge economy, looking at the main global trends, we can see a series of coexisting but sometimes contradictory processes: democratization, globalization, regionalization, multi-polarization, marginalization and fragmentation. All these influence the development of higher education to some extent and require 
the feedback of the higher education. In the new situation, what is the function of university and how to take the best use of university is an eternal issue.

\section{The Commonness and Specialty of Modern College and University Idea}

In the interactive relationship between the university and society, university not only has the aspect of commonness, but also has the aspect of specialty. These two aspects are not only interrelated, but also can restrict the other and transform into the other in some situation. The commonness of modern university, such as academic freedom, it is not only the key idea of a university, but also the soul of a university, at the some time, it is the most valuable foundation on which all university are based. No academic freedom, no real university. University Autonomy, which is closely related to academic freedom, is an institutional barrier to protect academic freedom from external encroachment. Academic freedom, university autonomy are the two basic pillars of the modern university idea. What's more, some responsibilities such as talent cultivation, scientific research, society service, cultural inheritance are not only the missions of the public university, but also the inescapable missions of the private university.

Because of the different developmental history, developmental type and developmental level of every school, the idea of each university presents the characteristic of deference on running a school. Different university ideas lead to different university styles and characteristics, and the developmental characteristics are the advantages of a university. Therefore, for every university, the idea of a university is developmental, specialty, it is necessary to combine the characteristics of the times and the situation of the school, so as to show the specialty of a university and make progress on innovation. As an important part of the higher education, of course, private university should follow the systematic key idea of university. But, in the aspects of history, position, model of cultivating the talent, mechanism of operation, and sources of funds, private college is quite different from the public university, it is urgent to explore and summarize the practical idea of running a university that is suitable for the actual situation of the universities and that can reflect the features of the modern times, so as to take the best use of it in the actual activities of running university, at the some time, to form the specialty of the universities and stride to the objective of being a high-level university.

\section{The Loss of Modern College and University Idea in Private Colleges and Universities}

\subsection{The position of running school is not accurate enough}

The deviation of the position of running a school is mainly expressed in these aspects as below: hankering after giant; chasing for setting the majors of high degree and high level but neglecting overall development; setting all kinds of disciplines and majors that are complete in range but weak in quality, and objective and model of cultivating talent are simplex. The position of university is unclear, majors and disciplines are similar, these problems are not conducive to the constant development of the private colleges and universities, at the some time, the problems aggravate the cut-throat competition of the private colleges and universities, and block the further and constant development of the private higher education.

\subsection{Failure to properly deal with the relationship between scale and quality}

How to deal with the relationship between scale and quality is still the key segment of the development of private colleges and universities. No large scale development, no the living basis of private colleges and universities; and no high-level expansion, the schools will be deep in living crisis. How to balance the relationship between scale and quality is the urgent problem that the private colleges and universities should solve.

\subsection{The conflict between the public welfare and the pursuit of interest is obvious.}

Compared with the public colleges and universities, most of the private colleges and universities raise funds by means of tuition fee from the students, loans from the banks and the incomes of the 
companies attach to the colleges or universities. The participation of private capital has brought vitality to the development of private higher education, but the profit-driven nature of the capital has made quite a number of private university organizers blindly cater to the market and pursue low cost and high income, forget the basic principle and basic value of education cause, ignore and neglect the nature of public welfare of education.

\subsection{The management mechanism of school juridical person should be improved urgently}

At present, although some private colleges and universities have established the board, but most members of the board are the relatives of the investors of the schools, there are few representatives who are the staff of the school but are not the relative of the investor in the board or council, this influence the democratization and rationality of decision-making. There are also some schools, the boards or councils keep a disharmonious relationship with the headmasters, there duties are not specific. The directors of the boards interferes more with the specific affairs of the schools, so that the headmasters of the schools can not execute their functions of teaching and administration independently.

\subsection{The teaching quality is uneven and the developmental task is heavy.}

The reform on curriculum and teaching of the private higher education lags behind, the cultivation of students' practical ability is difficult, and the teaching quality is difficult to reach the expected level. The structure of teachers is unreasonable and the team of teachers is unstable. The incentive mechanism of high-level talents is not perfect enough, and the system and environment of encouraging outstanding talents to stand out from the crowd need to be reformed and perfected.

\section{The Framework and Prospect of Modern College and University Idea in Private Colleges and Universities}

The modern universities in china, on one hand, they root in the fertile soil of Chinese traditional culture, form their own academic tradition and reflect the national characteristics of China. On the other hand, they should absorb the rich nutrition of the excellent culture of all nationalities in the world and follow the general principle of university development. In this way, the university can not only have deep inside information, but also learn from all kinds of advantages of other universities; in this way, the university could be vigorous and keep the constant development.

As the essential nature of higher education, public welfare is also the basic nature of private colleges and universities. To maintain the public welfare of education and to carry out this mission are directly related to the survival and development of private colleges and universities.

On the one hand, education has the features of complexity, it is difficult to measure, and it also has the features of long periodicity and stability, these conducive to the development of the private colleges and universities that highlight the welfare of education. Private colleges and universities that really insist on running schools for public welfare generally have long-term plans, they are not eager to achieve immediate benefits but fully take into account the complexity and long-term nature of education, so as to train outstanding talents and serve the economic and social development of the country as the first important task. Once the funds are invested, they become permanent educational assets, all of which are used for the further development of the school. This has laid a good economic foundation for the sustainable development of schools. On the other hand, the development of private colleges and universities can not be separated from the support of the government and the guarantee of policies. In order to get equal policy support of public colleges and universities, private schools must seek support through contributions, sincere understanding, and take the developmental path of public welfare.

China has experienced three stages in the concept of running a school, from running schools without communication before the reform and opening up policy to communicate with the outside after adopting the reform and opening up policy, and now in the stage of initiatively going out and entering the society to seek cooperation. 
"Education is a kind of service" has been deeply rooted in the people's mind. The students and society are the main clients of school education. Through teaching and scientific research, schools provide high-quality educational services to students and society, in order to maximize the efficiency of running a school.

Talent cultivation is the main objective of private colleges and universities. Under the guidance of service concept, we must bravely promote teaching reform; follow the principle of taking people as the centre; and the some time, explore the model of talent training, so as to seek the further development. First, it is necessary to close to the needs of society and to optimize the structure of the majors and disciplines. In particular, we should pay attention to the industrial structure and developmental trend of the service areas of the universities, pay attention to the level of economic and social development of the areas, and the demand for talents of the area, develop a number of specialized disciplines that are with strong adaptability, and that could meet the need for the scarce talents who can promote the regional development of economy and society. Second, it is also necessary to insist on "paying attention to academic theory, servicing the demand", and then, to reform boldly, to construct new knowledge system and serve the individualized development of students. Under the background of the popularization of higher education, the purpose of the public for receiving higher education is diversified, so it is necessary to deepen the reform, so at to cultivate the diversified talents and meet the individualized needs of students from the view of serving students' healthy growth. Third, it is necessary to create excellent class, and constantly improve the quality of teaching. By means of strengthening classroom management, improving teachers' structure, reforming teaching contents and teaching methods, we can cultivate and strengthen students' interest in learning, promote their enthusiasm for learning and improve the effectiveness of teaching activities.

Throughout the private higher education all over the world, there are several kinds of private colleges and universities such as research-oriented, teaching-oriented, the integration of the two kings, and applied technical universities, as well as private universities with the nature of vocational education. The scale of running a school includes junior college education, bachelor degree education, master and doctor degree education; full-time and part-time, education with record of formal schooling, and education without record of formal schooling. In contrast, private colleges and universities in China are almost all non-profit private colleges and universities, the main types of private schools are junior college education and bachelor degree education (only five have the qualification to recruit professional master's degree), the model of running a school is relatively simplex. The multi-level, multi-type and diversified demand of social and economic development determines that private colleges and universities must be diversified in position and development. Education with special features and high quality is not hierarchical, not classified; each type and level of education can reach the excellent level of quality education, and can be made into famous schools. Therefore, it is scientific and reasonable for private colleges and universities to highlight their own characteristics, build their own brands, and promote the development of their schools, no matter what type they belong to, what position they choose, as long as they can combine their own advantages. "What is suitable is the best".

\section{Acknowledgement}

Scientific Research Program Funded by Shaanxi Provincial Education Department (Program No. 13JZ075)

\section{References}

[1] Xiao Haitao. The Idea of a University[D]. Wu Han: Huazhong University of Science and Technology, 2000.

[2] Tian Jianguo. Discussion on the Idea of Modern University[J]. China Adult Education, 2006:(11). 
[3] Zhang Xisheng, Zhang Juan. Try to Discuss the Similarity and Specialty of the Idea of a University----and to Comment Some Phenomena of the Higher Education Circle of China[J]. Modern Education Science, 2005: (1):56.

[4] Li Zhao. To be Responsible for Society: Private Colleges and Universities Must Remember Their Mission[J]. Heilongjiang Research on Higher Education, 2009, (3): 99.

\author{
About the Authors: \\ Wang Guan(1964--), male, comes from Hancheng, Shaanxi Province. \\ Title: Researcher of Pedagogy, Associate Professor of Literature \\ Research Direction: Private Higher Education, Contemporary Literature and Writing \\ Zhang Yan(1980--), female, comes from Pu Tian, Fujian Province. \\ Title: Lecturer \\ Research Direction: Private Higher Education
}

